\title{
LEMAN-BAIKAL: REMOTE SENSING OF LAKES USING AN ULTRALIGHT PLANE
}

\author{
Y. Akhtman ${ }^{\dagger}$, D. Constantin ${ }^{\dagger}$, M. Rehak ${ }^{\dagger}$, V. Nouchi ${ }^{\dagger}$, G. Shinkareva ${ }^{\ddagger}$,

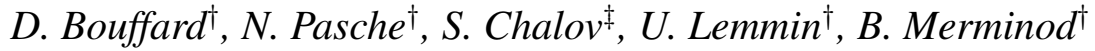 \\ †École Polytechnique Fédérale de Lausanne, Lausanne, Switzerland \\ ${ }^{\ddagger}$ Lomonosov Moscow State University, Moscow, Russian Federation
}

\begin{abstract}
The Leman-Baikal project constitutes an international SwissRussian collaborative research initiative in the field of physical limnology. The three-year framework involves the development and deployment of a novel multispectral and hyperspectral remote sensing platform optimised for the sensing of land and water surfaces from an ultralight aircraft. In this paper we discuss the developed remote sensing methodology and the initial obtained results.
\end{abstract}

Index Terms - Remote sensing, hyperspectral imaging, photogrammetry, limnology, ultralight plane

\section{INTRODUCTION}

Remote sensing technologies provide some of the most effective methods for the exploration and study of the Earth surface [1]. In particular, multispectral and hyperspectral space-bourn and airborne observations are widely used to study different natural and anthropogenic processes [2] including those pertaining to water bodies [3]. The recent technological advances that make remote sensing equipment ever more accessible have brought about a new surge in the interest towards the development of novel and powerful remote sensing methodologies. Of particular interest in this context is the emergence of multiscale analysis, where data from multiples sources: satellites, aircrafts and ground sampling measurements representing different spacial and temporal scales are correlated and jointly processed [4].

The lake Baikal area has a long history of successful application of the various remote sensing methods. For example, the transformation of landscapes was studied by Sutyrina using data from Advanced Very High Resolution Radiometer (AVHRR) and the Moderate Resolution Imaging

Both financial and logistic support of this study by the Foundation pour l'Etude des Eaux du Léman (FEEL), Ferring Pharmaceuticals, the Consulat Honoraire de la Fédération de Russie à Lausanne, as well as the Dr. Paulsen Foundation and the Lake Baikal Protection Fund is gratefully acknowledged. The authors are grateful for the help provided by D. Tuia and D. Ziegler of EPFL, as well as A. Ayurzhanaev, E. Garmaev, and A. Tulokhonov of BINM. Special thanks are due to the team of French and Russian ULM pilots F. Bernard, J. Couttet, A. Barisevsky, A. Sherbakov, V. Vikharev and N. Belyaev, who made this research possible.

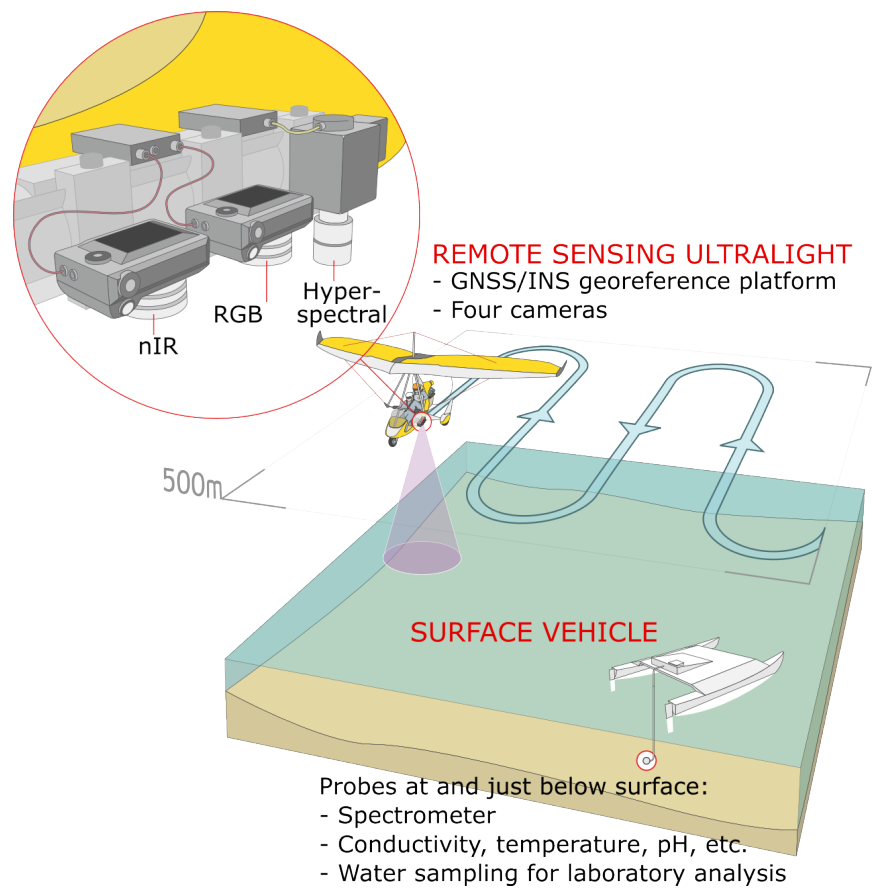

Fig. 1. Concurrent airborne and surface data acquisition.

Spectroradiometer (MODIS) [5]. The influences of climatic changes and human activity were further explored by Korytny et al. [6]. Mapping of distribution of air and water surface temperatures was done for the Lake Baikal using data from AVHRR [7]. Ivanov et al. studied the Selenga river delta area using Landsat data in aim to detect delta configuration changes from 1701 to 2000 [8].

Against this background, in this paper we discuss the methodology and the initial results obtained during the first phase of the Leman-Baikal project that took place during the spring and summer months of 2013 on lakes Geneva in Switzerland and Baikal in Russian Federation. The primarily aim of the project is to conduct a comparative study of the functioning of both lakes. The scientific objectives of the project include the analysis of hydrological processes, such as the runoff dynamics of both natural and anthropogenic origin, lake energy balance, and the study of processes pertaining to the land-water and air-water interfaces in lakes. 


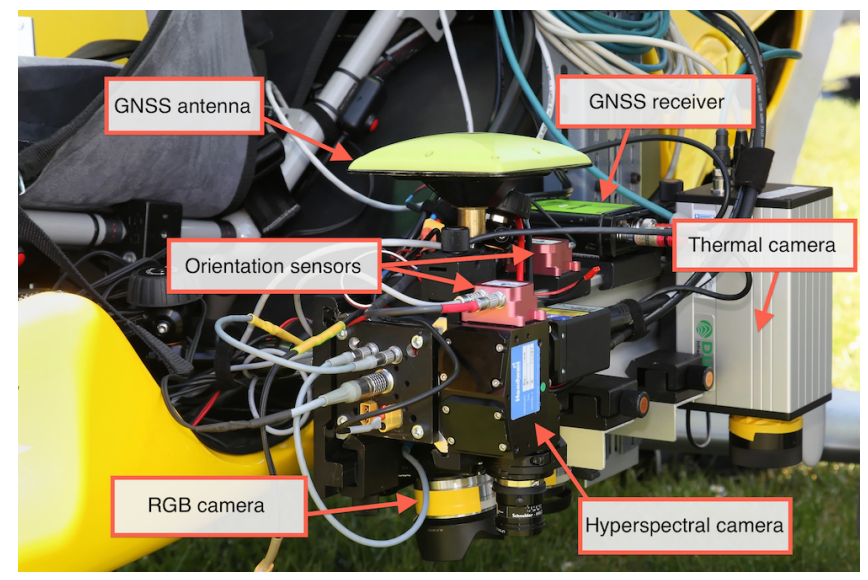

(a)

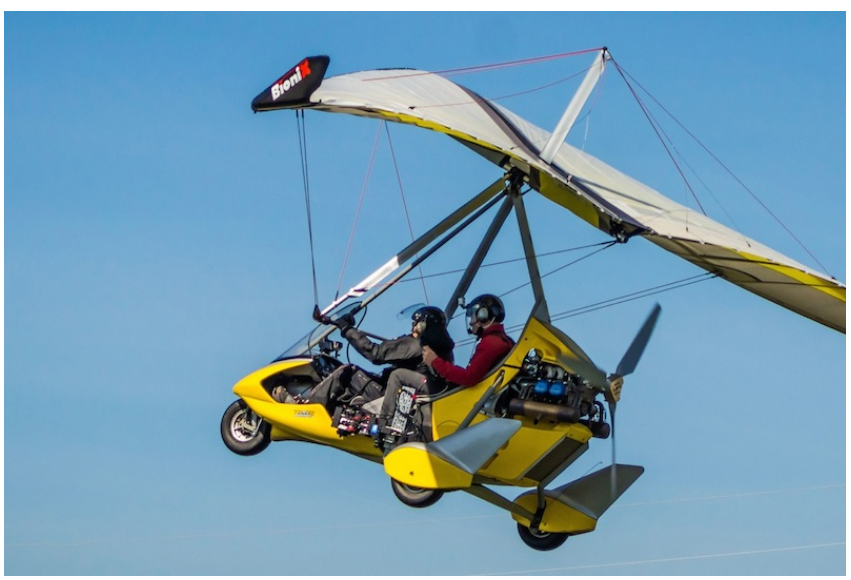

(b)

Fig. 2. Multispectral and hyperspectral remote sensing platform (a) installed on an Air Creation Tanarg 912S ultralight aircraft (b).

\section{METHODOLOGY}

The main principle of the research methodology is constituted by the concurrent acquisition of airborne wide-area and surface point-based data as illustrated in Figure 1. Specifically, we have employed the ultralight aircraft in order to carry an airborne remote sensing platform, and a boat equipped with a range of sensing and water sampling equipment.

As part of the Leman-Baikal project a remote sensing platform was developed to collect multispectral and hyperspectral observations of both land and water surfaces from ultralight aircraft. The platform is comprised of four cameras, auxiliary position and orientation sensors, as well as data recording equipment. Our main instrument is constituted by a Headwall Photonics Micro Hyperspec VNIR sensor. In addition, the platform includes two high-resolution RGB and near-infrared sensors based on consumer-grade Sony NEX5R cameras, as well as a thermal infrared sensor based on the DIAS Pyroview 640L Compact camera. The resultant remote sensing platform is portrayed in Figure 2 (a). As our airborne carrier we have utilised the Air Creation Tanarg ultralight aircraft depicted in Figure 2 (b).

The surface-based samples were used to produce a detailed characterisation of the water properties at sampling locations. Additionally, the reflected spectral response of the water surface at each sampling point is registered. The reflectance properties are correlated with the various water characteristics and the spectral response-based indicators for the various chemical and biological water properties are derived. The resultant spectral signature-based indicators are subsequently utilised in order to derive a wide-area maps of water properties using the multispectral and hyperspectral data collected with the use of the airborne remote sensing platform.

In this context, the concurrent airborne and surface based data acquisition methodology exemplified in Figures 3 and 4 is essential for the sake of calibration of the airborne data, as well as the analysis of data quality, accuracy and precision. Correspondingly, ground sampling sites were chosen within the trajectories of the aircraft where the strongest variability of water quality parameters could be observed. We used three radiometers to validate the hyperspectral acquisition from the ULM: the OceanOptics USB 2000+, the waterInsight WISP 3 , and the Ramses TriOS system. In addition, water quality parameters were measured with a Seabird CTD19+V2 for chlorophyll-a and turbidity and sub-surface water samples for the Yellow substances. This latter parameters are used as supervision in a neural network which interpret the ULM hyperspectral data in terms of water constituents.

\section{DATA PROCESSING CHAIN}

The airborne remote sensing data processing chain is being actively developed for the effective analysis of the material collected in the course of the various phases of the field campaign. The raw data is comprised of multiple data types including multispectral image sequences, hyperspectral line scan sequences, as well as auxiliary navigation data logs. The aim of the data processing methodology is the production of a data management system, which will facilitate access to synchronised, calibrated, as well as time and space referenced multimodal data.

For example, major steps that comprise the implemented hyperspectral data processing pipeline include:

- geometric and radiometric corrections of the individual scan lines that compensate for both lens- and sensorrelated radiometric and geometric distortions;

- atmospheric correction that accounts for the specific lighting conditions, as well as the effects inflicted by the downwelling and upwelling propagation of light through the atmosphere;

- evaluation of the surface reflectance from the irradiance 


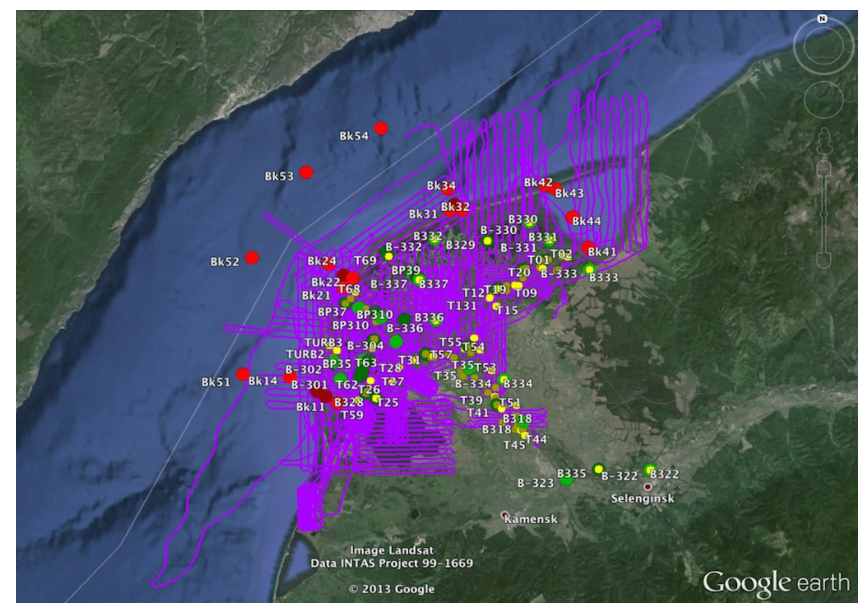

Fig. 3. Flight trajectories (purple) and in situ sampling sites (red, yellow and green) for the Selenga delta during the Lake Baikal phase of the Leman-Baikal project, which took place during July of 2013.

that takes into account specular effects and mitigate sun glint;

- DTM-based orthorectification and georeferencing.

The performance of the resultant data processing chain is exemplified in Figure 4 that details the flight trajectory, ground sampling sites, as well as the corresponding hyperspectral data obtained on March 7, 2014 on the eastern side of lake Geneva. It should be noted, however, that not all stages in the detailed pipeline have been completed thus far and the development remains a work in progress.

Furthermore, as part of the Leman-Baikal project we have developed and deployed a dedicated database system and a web-based GIS data management framework, which facilitates an effective and highly structured storage, search, retrieval and visualisation of multi-modal scientific data collected in the course of the field campaign.

\section{DATA ACQUISITION AND INITIAL RESULTS}

During the stage of the system development, as well as during the collection of the initial data, we conducted a series of flights in the area of Lake Geneva in western Switzerland in April and May of 2013. Our initial points of interest included the mouths of the Venoge and the Rhône rivers, which exhibit a particularly rich range of visually observable hydrological phenomena.

In the consecutive stage of the project, taking place during the months June and July of 2013, we have carried out a comprehensive field campaign in the area of the Selenga river delta in Lake Baikal, which is the largest freshwater reservoir on Earth and is located in the Southern Siberia region of the Russian Federation. The campaign was conducted in close collaboration with the Geography Faculty of

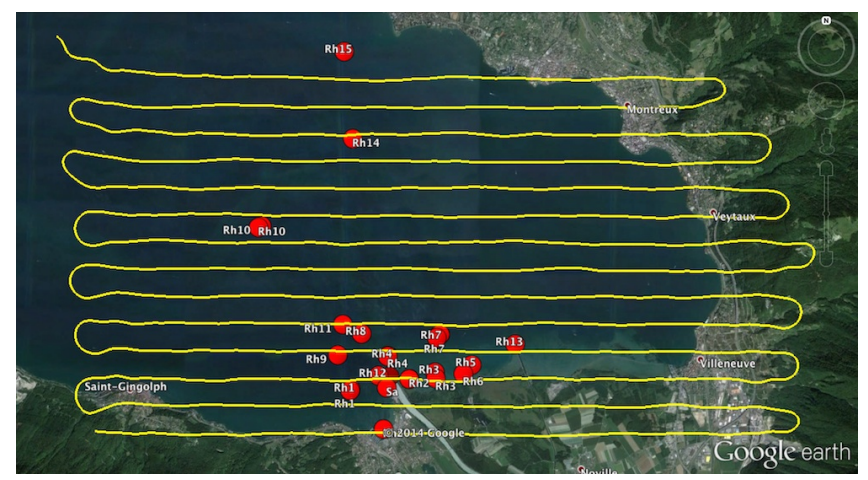

(a)

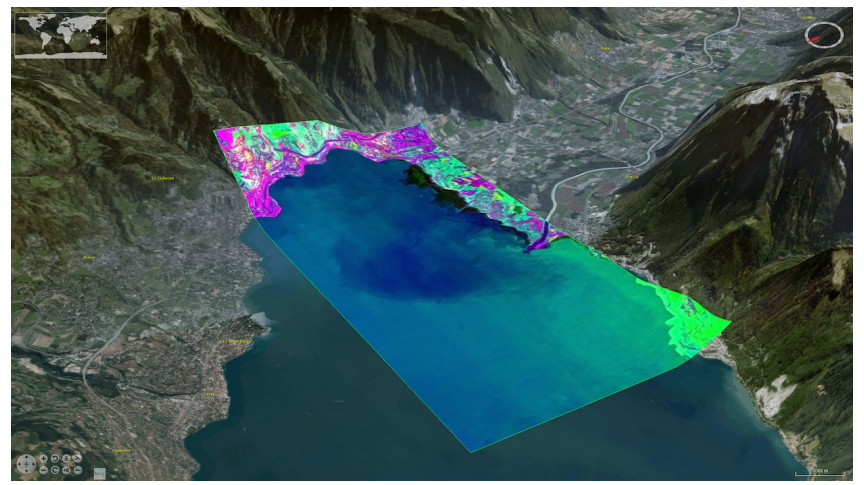

(b)

Fig. 4. Data acquisition campaign of March 7, 2014 over eastern side of Lake Geneva, Switzerland: (a) flight trajectory (yellow) and in situ sampling sites (red); (b) threedimensional visualisation of the orthorectified and georeferenced hyperspectral data.

the Moscow State University and the Institute of Nature Resource Management in Ulan Ude. Our airborne observations were complemented by extensive ground work, which included the collection and analysis of in situ samples, as well as the recording of the corresponding spectral reflectance signatures of the water surface.

The observations were further resumed on lake Geneva in March 2014 with the aim of recording the seasonal variations in the environmental state of the lake's surface and the associated hydrological processes. Given the large size of the acquired dataset, data processing is still underway. However, preliminary results show a high similarity of the spectra measured from the air and in situ from the lake surface. These encouraging results will soon allow assessment of the heterogeneity of water quality parameters on large portions of the two lakes, and to describe local mixing phenomena at a high spatial and temporal resolution.

Ground truthing resulted in 79 ground control points in Lake Geneva around Venoge and Rhone rivers, and 36 sites in the Selenga region of Lake Baikal. The initial analysis of the obtained hyperspectral data is exemplified in Figure 5 that represents the data recorder on March 7, 2014 in the east- 
ern side of lake Geneva. Specifically, Figure 5 (a) portrays the principle component analysis (PCA)-based visualisation of the hyperspectral data. Figure 5 (c) quantifies the particle distribution corresponding to a typical structure of the outflow of Rhone river in the lake. Notably, the data obtained on March 7 were collected at a time when the photosynthetic activity is still negligible in the lake and therefor our analysis showed no quantifiable chlorophyll distributions. The integrated RGB rendition of the hyperspectral data is provided in Figure 5 (b) for the reference.

\section{CONCLUSIONS AND FUTURE WORK}

In this paper we have presented the preliminary results obtained during the first year of the three year framework of the Leman-Baikal project.

The data acquisition campaigns resulted in the collection of the total of around 7 Terabytes of airborne remote sensing data covering the area in excess of $2000 \mathrm{~km}^{2}$, including more than 100 in situ sampling sites. The entire field campaign spanning both Lake Leman and Lake Baikal phases included over 83 hours of flight having an accumulate flight trajectory length in excess of $7,700 \mathrm{~km}$. In particular, the data collected to date is comprised by 580,000 airborne images and nearly $15,000,000$ hyperspectral scan lines.

The main focus during the first season of the project was on the development of the remote sensing equipment, as well as the corresponding data acquisition and processing methodologies. Our initial results show a great potential of the developed system. The analysis of the data collected during the 2013 season is ongoing, and the remaining two years of the project offer an outstanding opportunity for further scientific research.

\section{REFERENCES}

[1] J.B. Campbell and H.W. Randolph, Introduction to remote sensing, CRC Press, 2011.

[2] M.E. Schaepman, S.L. Ustin, A.J. Plaza, T.H. Painter, J. Verrelst, and S. Liang, "Earth system science related imaging spectroscopy - an assessment," Remote Sensing of Environment, vol. 113, pp. S123-S137, 2009.

[3] S. Koponen, J. Pulliainen, K. Kallio, and M. Hallikainen, "Lake water quality classification with airborne hyperspectral spectrometer and simulated meris data," Remote Sensing of Environment, vol. 79, no. 1, pp. 51-59, 2002.

[4] A. Lausch, M. Pause, I. Merbach, S. Zacharias, D. Doktor, M. Volk, and R. Seppelt, "A new multiscale approach for monitoring vegetation using remote sensing-based indicators in laboratory, field, and landscape," Environmental Monitoring and Assessment, vol. 185, no. 2, pp. 12151235, 2013.

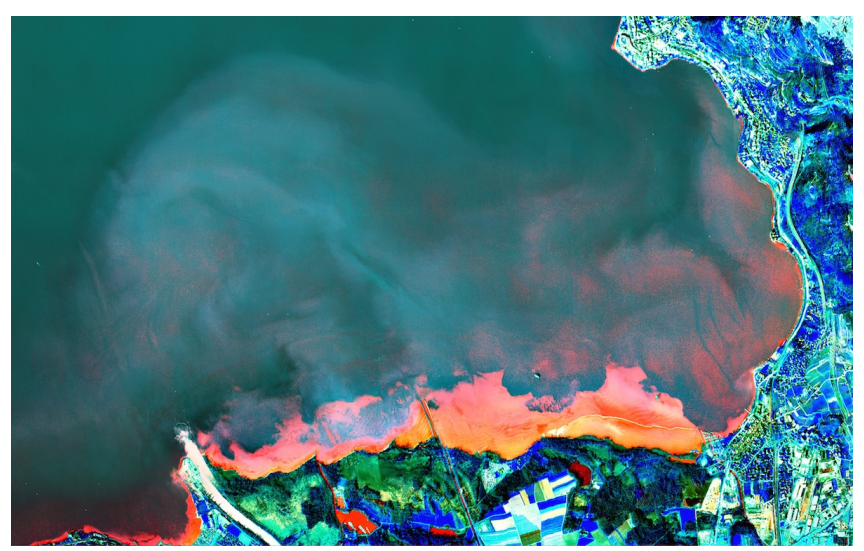

(a)

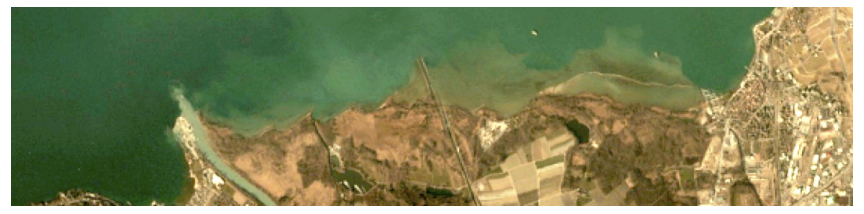

(b)

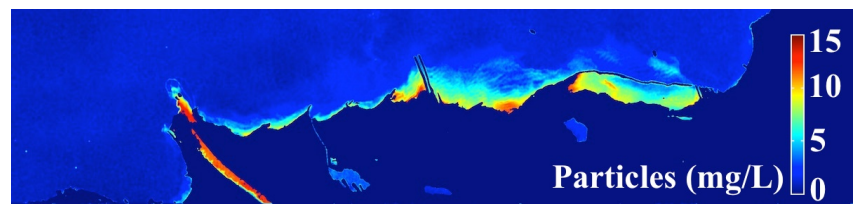

(c)

Fig. 5. Visualisations of the eastern side of Lake Geneva including the outflow of river Rhone based on the hyperspectral imaging data collected on March 7, 2014: (a) principle component analysis (PCA)-based false-colour; (b) integrated RGB; and (c) neural network-based estimation of the particle concentrations.

[5] E. Sutyrina, "Assesment of the transformation of landscapes in the catchment area of the Lake Baikal using satellite remote sensing data," Privolgskij scientific bulletin, vol. 2, no. 30, pp. 195-197, 2014.

[6] L.M. Korytny, O.I. Bazhenova, G.N. Martianova, and E.A. Ilyicheva, "The influence of climatic change and human activity on erosion processes in sub-arid watersheds in southern east siberia," Hydrological Processes, vol. 17, no. 16, pp. 3181-3193, 2003.

[7] E. Sutyrina, "Application of satellite data for the study of large inland water bodies (on the example of lakes Baikal and Hovsgol)," Scientific and practical journal "Bulletin of IrGSHA", vol. 57, pp. 57 - 60, 2013.

[8] V. Ivanov, V. Korotaev, and I. Labutina, "Morphology and dynamics of Selenga river delta," Moscow University Bulletin. Geography., vol. 5, no. 4, pp. 48 - 54, 2007. 